\title{
Antimicrobial resistance profiles of 5 common bovine mastitis pathogens in large Chinese dairy herds
}

\author{
Jia Cheng, ${ }^{1 *}$ Weijie Qu, ${ }^{2 *}$ Herman W. Barkema, ${ }^{3}$ Diego B. Nobrega, ${ }^{3}$ Jian Gao, ${ }^{1}$ Gang Liu, ${ }^{1}$ Jeroen De Buck, ${ }^{3}$ \\ John P. Kastelic, ${ }^{3}$ Hong Sun, ${ }^{4}$ and Bo Han ${ }^{1} \dagger$ \\ ${ }^{1}$ Department of Clinical Veterinary Medicine, College of Veterinary Medicine, China Agricultural University, Beijing 100193, P.R. China \\ ${ }^{2}$ College of Veterinary Medicine, Yunnan Agricultural University, Kunming 650201, P.R. China \\ ${ }^{3}$ Department of Production Animal Health, Faculty of Veterinary Medicine, University of Calgary, Calgary, AB, Canada T2N 4N1 \\ ${ }^{4}$ China Animal Husbandry Industry Co. Ltd., Beijing 100070, P.R. China
}

\section{ABSTRACT}

The prevalence of antimicrobial resistance (AMR) is increasing in human and animal pathogens, becoming a concern worldwide. However, prevalence and characteristics of AMR of bovine mastitis pathogens in large Chinese dairy herds are still unclear. Therefore, our objective was to determine the AMR profile of bacteria isolated from clinical mastitis in large $(>500$ cows) Chinese dairy herds. A total of 541 isolates of the 5 most common species, Staphylococcus aureus (n $=103$ ), non-aureus staphylococci (NAS; $\mathrm{n}=107$ ), Streptococcus species $(\mathrm{n}=101)$, Klebsiella species $(\mathrm{n}$ $=130)$, and Escherichia coli $(\mathrm{n}=100)$, isolated from bovine clinical mastitis on 45 dairy farms located in 10 provinces of China were included. Presence of AMR was determined by minimum inhibitory concentrations using the microdilution method. Prevalence of multidrug resistance (resistance to $>2$ antimicrobials) was $27 \%(148 / 541)$. A very wide distribution of minimum inhibitory concentrations was screened in all isolates, including Staph. aureus isolates, which were resistant to penicillin (66\%). In addition, NAS (30\%) were more resistant than Staph. aureus to oxacillin (84\%), penicillin $(62 \%)$, tetracycline $(34 \%)$, and clindamycin (33\%). Prevalence of resistance to tetracycline was high (59\%) in Streptococcus spp. Additionally, prevalence of resistance of both E. coli and Klebsiella spp. was high to amoxicillin/clavulanate potassium (81 and 38\%, respectively), followed by tetracycline (only Klebsiella spp. $32 \%)$. A high proportion $(27 \%)$ of isolates were multidrug resistant; the most frequent combinations were clindamycin-cefalexin-tetracycline or enrofloxacin-

Received May 30, 2018.

Accepted November 26, 2018.

*These authors contributed equally to this work.

†Corresponding author: hanbo@cau.edu.cn cefalexin-penicillin patterns for Staph. aureus; enrofloxacin-oxacillin-penicillin-tetracycline patterns for NAS; clindamycin-enrofloxacin-tetracycline patterns for Streptococcus spp.; amoxicillin/clavulanate potassiumceftiofur-polymyxin B patterns for Klebsiella spp.; and amoxicillin/clavulanate potassium-ceftiofur-polymyxin B patterns for E. coli. Resistance for 4 kinds of antimicrobials highly critical for human medicine, including daptomycin, vancomycin, imipenem, and polymyxin $\mathrm{B}$, ranged from 0 to $24 \%$. In conclusion, prevalence of AMR in mastitis pathogens was high on large Chinese dairy farms, potentially jeopardizing both antimicrobial efficacy and public health. Results of this study highlighted the need for improvements in antimicrobial stewardship and infection control programs in large Chinese dairy farms to reduce emergence of AMR.

Key words: antimicrobial resistance, minimum inhibitory counts, multidrug resistance, bovine mastitis, China

\section{INTRODUCTION}

Mastitis is a major economic burden on the dairy industry, affecting milk production and milk quality (Abebe et al., 2016; Hogeveen and Van Der Voort, 2017). Numerous microorganisms associated with cases of mastitis have been isolated (Krömker and Leimbach, 2017; Vakkamäki et al., 2017); the most frequently isolated pathogens associated with clinical mastitis (CM) in China are Escherichia coli, Klebsiella spp., NAS, Streptococcus dysgalactiae, and Staphylococcus aureus (Gao et al., 2017). Identification of pathogens causing $\mathrm{CM}$ enables appropriate choices for antimicrobial treatment (Pinzón-Sánchez et al., 2011) and preventive mastitis management. Antimicrobials are used in the dairy industry for prevention and control of mastitis and other bacterial diseases affecting dairy cows (Oliver and Murinda, 2012). Therefore, dependence on antimicrobials has become a widespread phenomenon on dairy farms. 
Antimicrobial resistance (AMR) occurs when microorganisms are able to overcome effects of antimicrobials that were effective in the past. Based on EARS-Net data in 2016, AMR remains a serious threat to public health in Europe (ECDC, 2017). Additionally, AMR is one of the biggest threats to global health, food security, and development (WHO, 2015).

In 2010, China had the largest share of global antimicrobial use in food animal production (23\%), with projections for use of $30 \%$ by 2030 (Van Boeckel et al., 2015). Furthermore, AMR is becoming a serious healthcare problem, with high resistance rates of most common bacteria to clinically important antimicrobial agents (Shi et al., 2010; Xiao et al., 2011; Wang et al., 2015).

Prevalence of AMR in clinical bovine mastitis pathogens has been investigated numerous times recently in China, including regional results for Staph. aureus (Gao et al., 2012; Liu et al., 2017), E. coli (Liu et al., 2014), and Strep. dysgalactiae (Zhang et al., 2018b). However, to our knowledge a nationwide survey has apparently never been performed. The objective of the present study was to determine AMR profiles of 5 predominant bacteria isolated from CM in large Chinese dairy herds: Staph. aureus, NAS, Streptococcus spp., E. coli, and Klebsiella spp.

\section{MATERIALS AND METHODS}

\section{Statement of Ethics}

The present study was conducted according to the ethical guidelines of China Agricultural University (CAU; Beijing, China). Before start of the study, ethical approval was granted by the departmental committee of the College of Veterinary Medicine, CAU.

\section{Herds and Sampling}

Details of collected samples are presented in Table 1. One hundred ninety-eight isolates, including Staph. aureus $(\mathrm{n}=77)$, Streptococcus $\mathrm{spp} .(\mathrm{n}=3)$, Escherichia coli $(\mathrm{n}=47)$, and Klebsiella spp. $(\mathrm{n}=71)$, used in this study were collected (March 2014 to September 2016) during a previous study on the incidence of CM in large (>500 cows) Chinese dairy herds (Gao et al., 2017); an additional $343 \mathrm{CM}$ isolates, including Staph. aureus $(\mathrm{n}=26)$, NAS $(\mathrm{n}=107)$, Streptococcus $\mathrm{spp} .(\mathrm{n}=98)$, E. coli $(\mathrm{n}=53)$, and Klebsiella spp. $(\mathrm{n}=59)$, were collected from October 2016 to July 2017. In total, 45 dairy herds from herds submitting CM samples to the CAU mastitis laboratory were randomly included until a minimum of 100 isolates per bacterial group, Staph. aureus, Streptococcus spp., NAS, Klebsiella spp., and E. coli, were available for analysis. Briefly, milk samples were collected, according to National Mastitis Council (NMC, 1999) guidelines, from every udder quarter (1 sample per quarter) with $\mathrm{CM}$, and diagnosed on the basis of visual abnormality and inflammation of the udder or its milk secretion. Samples were collected in sterile bottles $(5-10 \mathrm{~mL})$ and transported on ice to the mastitis laboratory at the CAU. Recurrent CM cases $(<14 \mathrm{~d}$ apart), as well as repeated cases in same quarters, were not included.

\section{Isolates}

Upon arrival at the laboratory, all frozen samples were thawed at room temperature. Microbiological procedures were conducted as described by Ali et al. (2017) and Gao et al. (2017). Briefly, $10 \mu \mathrm{L}$ of milk from each sample was plated onto a tryptic soy agar (Beijing Aoboxing Biotechnology Co. Ltd., Beijing,

Table 1. Distribution of 541 bacteria isolated from clinical mastitis in 45 large Chinese dairy herds

\begin{tabular}{|c|c|c|c|c|c|c|c|c|c|c|}
\hline \multirow[b]{2}{*}{ Province } & \multicolumn{2}{|c|}{$\begin{array}{c}\text { Staphylococcus } \\
\text { aureus }\end{array}$} & \multicolumn{2}{|c|}{ NAS } & \multicolumn{2}{|c|}{$\begin{array}{l}\text { Streptococcus } \\
\text { spp. }\end{array}$} & \multicolumn{2}{|c|}{$\begin{array}{l}\text { Escherichia } \\
\text { coli }\end{array}$} & \multicolumn{2}{|c|}{$\begin{array}{l}\text { Klebsiella } \\
\text { spp. }\end{array}$} \\
\hline & Herds & Isol. ${ }^{1}$ & Herds & Isol. & Herds & Isol. & Herds & Isol. & Herds & Isol. \\
\hline Beijing & 3 & 5 & 2 & 2 & 2 & 4 & 3 & 7 & 3 & 6 \\
\hline Guangdong & 2 & 6 & 1 & 8 & 3 & 6 & 3 & 9 & 2 & 4 \\
\hline Hebei & 6 & 13 & 7 & 31 & 5 & 20 & 5 & 24 & 13 & 35 \\
\hline Heilongjiang & 2 & 44 & 2 & 32 & 14 & 39 & 6 & 27 & 4 & 9 \\
\hline Henan & 2 & 3 & 2 & 6 & 5 & 8 & 2 & 4 & 2 & 6 \\
\hline Liaoning & 2 & 12 & - & - & - & - & 2 & 5 & 3 & 13 \\
\hline Inner Mongolia & 6 & 13 & 6 & 22 & 7 & 15 & 5 & 18 & 10 & 32 \\
\hline Shandong & 1 & 1 & 2 & 4 & 4 & 6 & 2 & 6 & 4 & 13 \\
\hline Shanxi & 2 & 6 & 1 & 2 & 1 & 3 & - & - & 2 & 8 \\
\hline Tianjin & - & - & - & - & - & - & - & - & 2 & 4 \\
\hline Total & 26 & 103 & 23 & 107 & 41 & 101 & 28 & 100 & 45 & 130 \\
\hline
\end{tabular}

${ }^{1}$ Number of clinical mastitis isolates. 
China) with $5 \%$ sheep blood plate (Beijing Solarbio Science and Technology Co. Ltd., Beijing, China) and then incubated $\left(37^{\circ} \mathrm{C}\right)$ for 24 to $48 \mathrm{~h}$. Samples were considered culture-positive if 1 or more colonies were observed $(\geq 100 \mathrm{cfu} / \mathrm{mL})$. Milk samples yielding 2 bacterial species were grouped as a mixed culture, whereas samples yielding $>2$ bacterial species were considered contaminated (Verbeke et al., 2014). Preliminary isolation and identification of bacteria was performed using procedures of Mastitis Diagnostic Laboratory of China Agriculture University (Beijing, P.R. China) as described in Gao et al. (2017). Subsequently, E. coli, Streptococcus spp., NAS, and Klebsiella spp. were confirmed by $16 \mathrm{~S}$ rRNA sequencing (Frank et al., 2008). Streptococcus spp. included Streptococcus agalactiae (n $=28)$, Streptococcus uberis $(\mathrm{n}=29)$, and Streptococcus dysgalactiae $(\mathrm{n}=44)$. Finally, all isolates were stored at $-80^{\circ} \mathrm{C}$.

\section{Recovery of Isolates}

First, bacteria were recovered on a tryptic soy agar plate and incubated at $37^{\circ} \mathrm{C}$ for $24 \mathrm{~h}$. A single colony was then transferred into Mueller-Hinton Broth (Beijing Aoboxing Biotechnology Co. Ltd.) medium (5\% bovine serum added for Streptococcus spp.) and shaken at $37^{\circ} \mathrm{C}$ for $12 \mathrm{~h}$. A bacterial turbidimeter (WGZ-2-XJ, Shanghai Xinrui Instruments and Meters Co. Ltd., Shanghai, P.R. China) was used to adjust the suspension to a density equivalent to a $0.5 \mathrm{McFarland}$ standard, which was used for the MIC determination.

\section{MIC and PCR}

Phenotypic AMR was obtained using a microdilution method for antimicrobials commonly administered to dairy cattle and humans, following Clinical Laboratory and Standards Institute (CLSI) guidelines (Table 2; CLSI, 2017). Antimicrobials and concentrations evaluated for gram-positives included cephalexin (0.03-64 $\mu \mathrm{g} / \mathrm{mL})$, tetracycline $(0.03-64 \mu \mathrm{g} / \mathrm{mL})$, penicillin $(0.03-64 \mu \mathrm{g} / \mathrm{mL})$, and vancomycin $(0.03-64 \mu \mathrm{g} / \mathrm{mL})$. Additionally, for ceftiofur, cefquinome, enrofloxacin, oxacillin, clindamycin, amoxicillin/clavulanate potassium (amoxi/clav), and daptomycin, a concentration of 0.015 to $64 \mu \mathrm{g} / \mathrm{mL}$ was used for streptococci, whereas a concentration of 0.03 to $64 \mu \mathrm{g} / \mathrm{mL}$ was used for staphylococci (Staph. aureus and NAS). Subsequently, oxacillin-resistant NAS with MIC values for oxacillin of 0.5 to $2 \mathrm{mg} / \mathrm{L}$ were tested for presence of the mecA gene using PCR, as reported (CLSI, 2017). For gramnegative bacteria, MIC of 8 antimicrobials were tested: ceftiofur $(0.03-128 \mu \mathrm{g} / \mathrm{mL})$, cefquinome $(0.03-128 \mu \mathrm{g} /$ $\mathrm{mL})$, enrofloxacin $(0.03-64 \mu \mathrm{g} / \mathrm{mL})$, amoxi/clav (0.03$128 \mu \mathrm{g} / \mathrm{mL})$, tetracycline $(0.03-128 \mu \mathrm{g} / \mathrm{mL})$, kanamycin $(0.03-128 \mu \mathrm{g} / \mathrm{mL})$, imipenem $(0.03-64 \mu \mathrm{g} / \mathrm{mL})$, and polymyxin B $(0.03-128 \mu \mathrm{g} / \mathrm{mL})$. Positive controls (antimicrobial-free wells) were included in all plates. Included as quality control strains were Staph. aureus ATCC 29213 for Staph. aureus and NAS, Streptococcus spp. ATCC 19615, E. coli ATCC 25922, and Klebsiella spp. ATCC 700603.

Cephalexin, ceftiofur, cefquinome, enrofloxacin, oxacillin, clindamycin, tetracycline, and kanamycin were obtained from Ehrenstorfer Biotechnology Co. Ltd. (Augsburg, Germany); vancomycin, polymyxin B, and amoxi/clav were obtained from National Institutes for Food and Drug Control (Beijing, China); and penicillin, daptomycin, and imipenem were obtained from Shanghai Yuanye Biotechnology Co. Ltd. (Shanghai, China). We determined values for various isolate-antimicrobial combinations representing the minimum concentration of an antimicrobial that inhibited the visible growth of $\geq 50$ and $\geq 90 \%$ of microorganisms ( $\mathbf{M I C} \mathbf{5 0}_{\mathbf{5 0}}$ and $\mathbf{M I \mathbf { C } _ { \mathbf { 9 0 } }}$, respectively).

Resistance was defined according to CLSI (2013, 2017) or EUCAST (2015) with slight modifications. If no CLSI breakpoint existed, EUCAST cutoff values were used (Table 2). Additionally, if specific cutoff values were not available for a particular species (e.g., Klebsiella spp. as a group), cut-value of the family (Enterobacteriaceae) were used. Isolates were classified as resistant on the basis of clinical breakpoints (CLSI, 2013, 2017); AMR was defined as nonsusceptibility to a given antimicrobial by combining intermediate and resistant categories into a single category. Therefore, isolates with MIC values equal or above the intermediate breakpoint were classified as resistant. Multidrug resistance (MDR) was defined as resistance to $\geq 3$ antimicrobials (Magiorakos et al., 2012).

For each antimicrobial agent and bacterial species, $\mathrm{MIC}_{50}, \mathrm{MIC}_{90}$ and resistant rate, defined as number of resistant isolates divided by total number of isolates tested, were calculated using descriptive statistics.

\section{RESULTS}

\section{Isolates}

Five hundred forty-one isolates were used: 103 Staph. aureus from 26 dairy herds in 9 provinces, 107 NAS from 23 dairy herds in 8 provinces, 101 Streptococcus spp. from 41 dairy herds in 8 provinces, 100 E. coli form 28 dairy herds in 8 provinces, and 130 Klebsiella spp. from 45 dairy herds in 10 provinces in China (Table 1 ). 


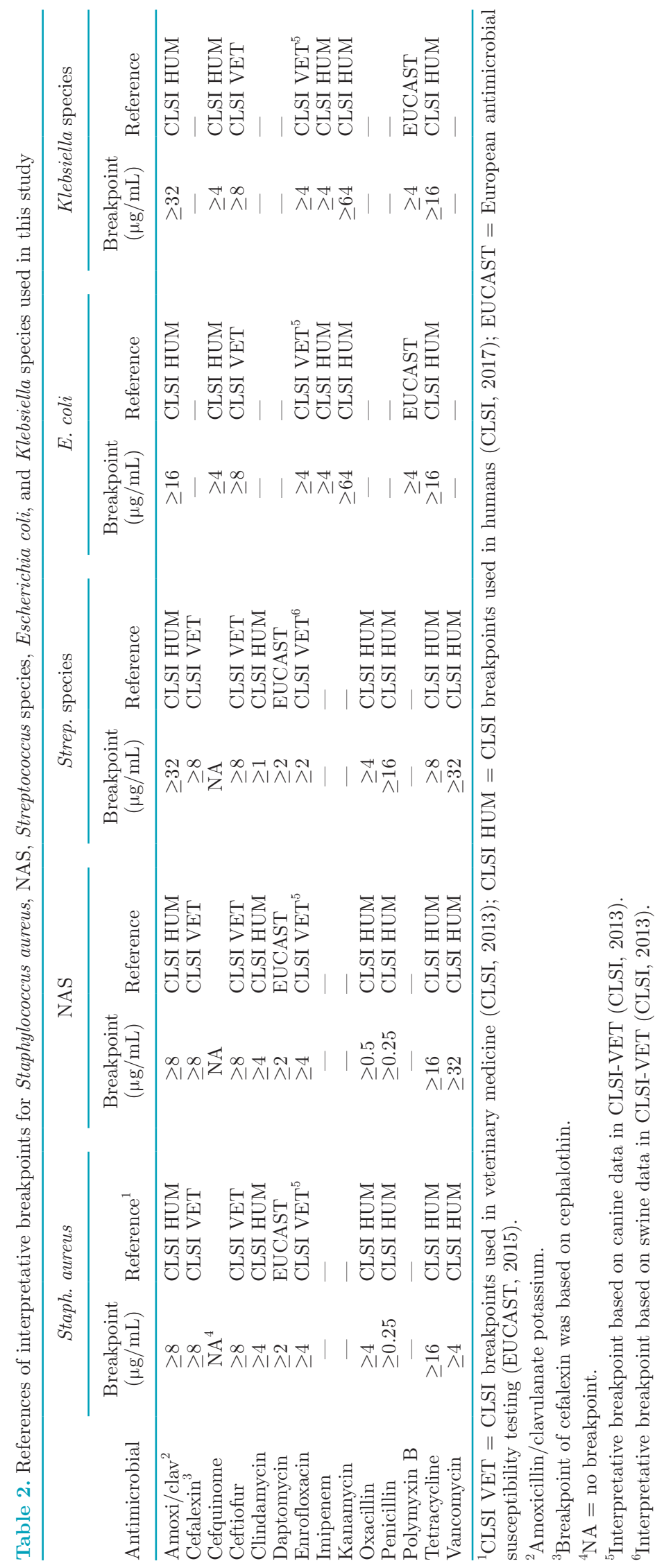




\section{Staphylococcus aureus}

For the 103 Staph. aureus isolates, MIC of antibiotics tested had a very wide distribution; $\mathrm{MIC}_{90}$ values were at least 2 times dilutions of its $\mathrm{MIC}_{50}$ values (Table 3). Except for penicillin $(>64 \mu \mathrm{g} / \mathrm{mL}), \mathrm{MIC}_{90}$ values were less than or equal to the highest antimicrobial concentration tested. Additionally, the lowest $\mathrm{MIC}_{90}$ value of Staph. aureus to these 11 antibiotics was for daptomycin and vancomycin $(1 \mu \mathrm{g} / \mathrm{mL})$. In Staph. aureus isolates, prevalence of resistance was highest for penicillin (66\%), followed by cefalexin (32\%), clindamycin (19\%), oxacillin (18\%), tetracycline (18\%), amoxi/clav (17\%), ceftiofur (16\%), enrofloxacin (10\%), daptomycin $(8 \%)$, and vancomycin (3\%). A total of $34(33 \%)$ isolates were MDR (Supplemental Table S1; https://doi.org/10.3168/jds.2018-15135), in which 2, 4, 6,10 , and 12 isolates were resistant to $7,6,5,4$, and 3 antimicrobials, respectively. One isolate had an amoxi/ clav-clindamycin-daptomycin-oxacillin-penicillin-vancomycin resistance pattern (Supplemental Table S1). Additionally, clindamycin-cephalexin-tetracycline and enrofloxacin-cephalexin-penicillin resistance patterns were present in top 2 isolates (both 3 isolates).

\section{NAS}

Regarding the 107 NAS isolates, MIC of all kinds of antimicrobials also had a very wide distribution (Table 4). The $\mathrm{MIC}_{90}$ of clindamycin and daptomycin was higher than the highest concentration $(64 \mu \mathrm{g} / \mathrm{mL})$ tested. All $\mathrm{MIC}_{90}$ values were $\geq 4$ dilutions higher than its $\mathrm{MIC}_{50}$ values. For these 11 antibiotics, the lowest $\mathrm{MIC}_{90}$ value of NAS was for ceftiofur $(4 \mu \mathrm{g} / \mathrm{mL})$, whereas the highest value was for clindamycin $(>64 \mu \mathrm{g} /$ $\mathrm{mL})$ or daptomycin $(>64 \mu \mathrm{g} / \mathrm{mL})$. Additionally, NAS were most often resistant to oxacillin (84\%), followed by penicillin (62\%), tetracycline (34\%), clindamycin (33\%), enrofloxacin (23\%), daptomycin (21\%), vancomycin $(20 \%)$, cefalexin (15\%), amoxi/clav (12\%), and ceftiofur (9\%). Additionally, among oxacillin-resistant strains, 67 strains carried the mecA gene. Strains with MIC value 0.5 to $2 \mu \mathrm{g} / \mathrm{mL}$ to oxacillin all carried the mecA gene. In total, $56 \%(60 / 107)$ of NAS isolates were MDR (Supplemental Table S1; https:// doi.org/10.3168/jds.2018-15135). Two, 1, 5, 5, 11, 16, and 20 isolates were resistant to $9,8,7,6,5,4$, and 3 antimicrobials, respectively. Furthermore, 1 isolate exhibited a resistance pattern composed of 9 antimicrobials: amoxi/clav-clindamycin-daptomycin-ceftiofurcephalexin-oxacillin-penicillin-tetracycline-vancomycin (Supplemental Table S1; https://doi.org/10.3168/jds .2018-15135). Five and 4 isolates had resistance patterns to nrofloxacin-oxacillin-penicillin-tetracycline and

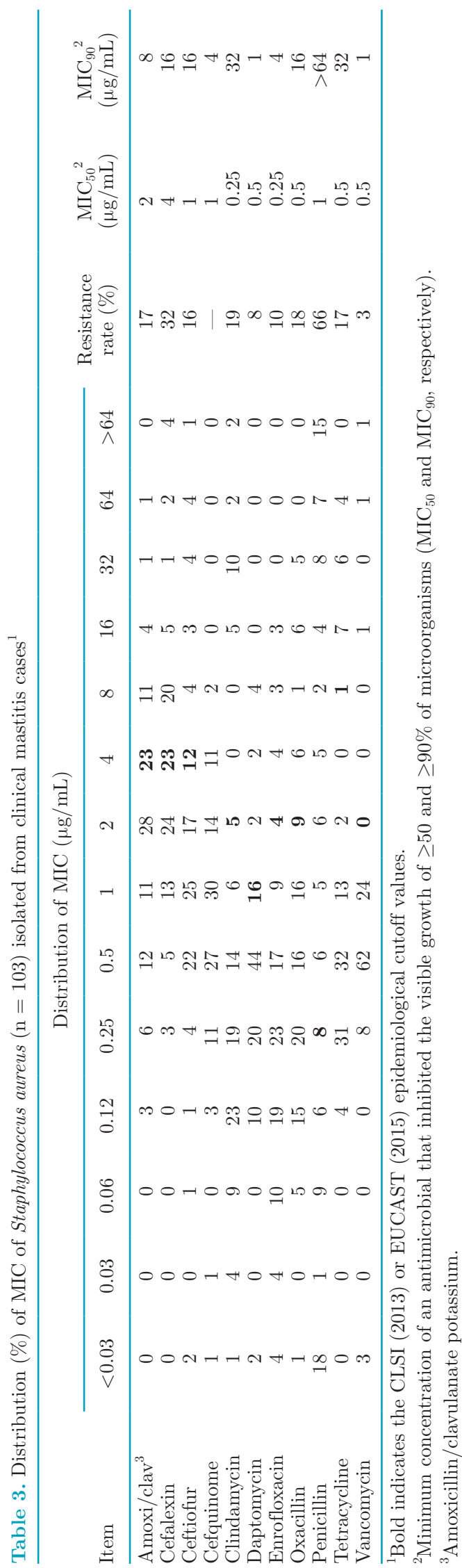




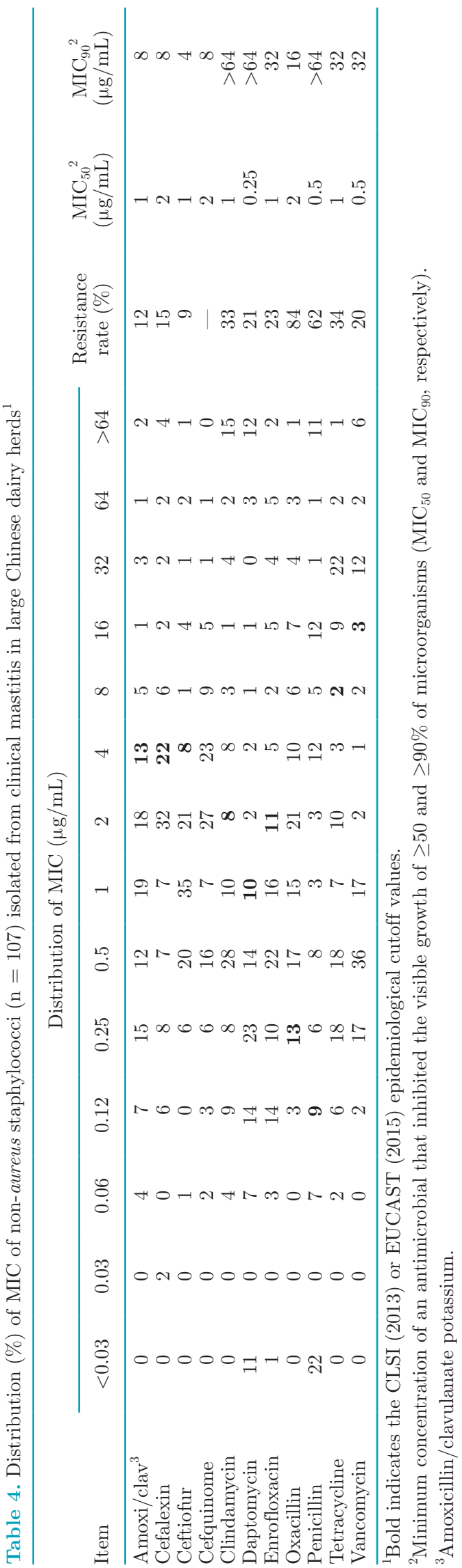

oxacillin-penicillin-tetracycline, respectively, the most frequent patterns we observed.

\section{Streptococcus Species}

In the 101 Streptococcus spp. isolates, the $\mathrm{MIC}_{90}$ value of clindamycin was higher than the highest concentration $(64 \mu \mathrm{g} / \mathrm{mL})$ tested (Table 5). All $\mathrm{MIC}_{90}$ values were $\geq 2$ dilutions higher than $\mathrm{MIC}_{50}$ values. The lowest $\mathrm{MIC}_{90}$ value was for cefquinome and penicillin $(0.25 \mu \mathrm{g} / \mathrm{mL})$, whereas the highest value was for clindamycin $(>64 \mu \mathrm{g} / \mathrm{mL})$. Resistance of Streptococcus spp. to tetracycline was most prevalent $(59 \%)$, followed by clindamycin $(29 \%)$, cefalexin $(19 \%)$, oxacillin $(16 \%)$, enrofloxacin (8\%), vancomycin (8\%), daptomycin (5\%), amoxi/clav (3\%), penicillin (2\%), and ceftiofur (1\%). In total, $21 \%$ (21/101) of isolates were MDR; 2, 7, and 12 isolates were resistant to 5,4 , and 3 antimicrobials, respectively (Supplemental Table S1; https://doi.org/10 $.3168 /$ jds.2018-15135). Furthermore, we noted 2 resistance patterns of 5 antimicrobials, exhibiting an amoxi/ clav-clindamycin-cephalexin-oxacillin-tetracycline or clindamycin-cephalexin-oxacillin-tetracycline resistance pattern (Supplemental Table S1). Clindamycin-enrofloxacin-tetracycline was the most frequent resistance pattern with 3 isolates.

\section{Klebsiella Species}

In these 130 Klebsiella spp. isolates, we noted differences in MIC distributions for various antimicrobials (Table 6). Except for amoxi/clav or ceftiofur, the $\mathrm{MIC}_{90}$ values of other antimicrobials used in this experiment were $\geq 2$ dilutions higher than $\mathrm{MIC}_{50}$ values. The lowest $\mathrm{MIC}_{90}$ value of the 8 antibiotics was for enrofloxacin and imipenem $(1 \mu \mathrm{g} / \mathrm{mL})$, whereas the highest value was for amoxi/clav and ceftiofur $(>128 \mu \mathrm{g} / \mathrm{mL})$. Resistance in Klebsiella spp. was most prevalent to amoxi/clav (38\%), followed by tetracycline $(32 \%)$, polymyxin B $(24 \%)$, ceftiofur (21\%), kanamycin (15\%), cefquinome (10\%), enrofloxacin (2\%), and imipenem (1\%). Furthermore, a total of $25(19 \%)$ isolates were resistant to $>2$ antimicrobials carrying amoxi/clav-ceftiofur-polymyxin B, amoxi/clav-ceftiofur-cefquinome-tetracycline-kanamycin-polymyxin B, and amoxi/clav-ceftiofur-polymyxin $\mathrm{B}$ resistance patterns, which were observed in 5, 3, and 3 isolates, respectively (Supplemental Table S1; https:/ /doi.org/10.3168/jds.2018-15135).

\section{Escherichia coli}

The MIC values of $100 \mathrm{E}$. coli isolates from 100 individual cows on 28 dairy farms in 8 provinces of China were determined. Total $\mathrm{MIC}_{90}$ values covered in this 

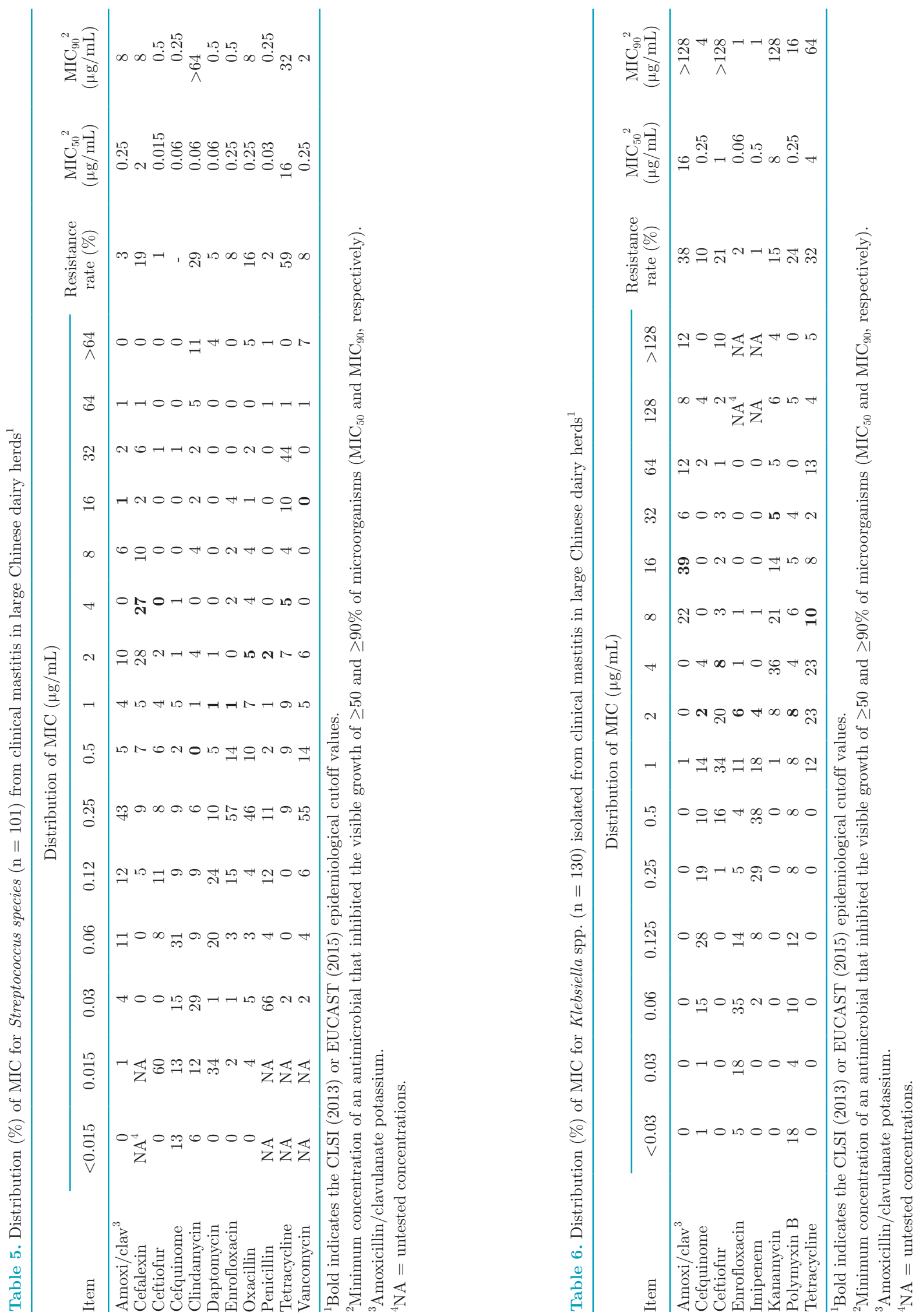
experiment were $\geq 2$ dilutions higher than its $\mathrm{MIC}_{50}$ values (Table 7 ). Additionally, the lowest $\mathrm{MIC}_{90}$ value of these 8 antibiotics was for cefquinome and enrofloxacin $(0.25 \mu \mathrm{g} / \mathrm{mL})$, whereas the highest value was for amoxi/clav and polymyxin B $(128 \mu \mathrm{g} / \mathrm{mL})$. Escherichia coli isolates had the highest proportion of resistance to amoxi/clav (81\%), followed by polymyxin B (19\%), ceftiofur (16\%), tetracycline (10\%), kanamycin (6\%), and cefquinome (1\%). No E. coli isolate was resistant to enrofloxacin or imipenem. Among 100 E. coli, $8 \%$ of isolates were resistant to $\geq 3$ antimicrobials, in which isolates carried amoxi/clav-ceftiofur-polymyxin B, amoxi/clav-ceftiofur-polymyxin B-tetracycline, amoxi/ clav-kanamycin-tetracycline, or cefquinome-ceftiofurpolymyxin B resistance pattern, present in 4,2 , 1, and 1 isolates, respectively (Supplemental Table S1; https:/ /doi.org/10.3168/jds.2018-15135).

\section{DISCUSSION}

Bacterial infections are the predominant cause of bovine mastitis; therefore, antimicrobial therapy is commonly implemented for mastitis prevention and control (Oliver et al., 2011). Prompt treatment with effective antimicrobials is especially important to reduce the risk of a fatal outcome, especially for invasive bacterial infections (ECDC, 2017). Unfortunately, despite best possible antimicrobial treatments, failures of bacteriological cure are common, with AMR implicated in low cure rates (Barkema et al., 2006). The World Health Organization has stated that any use of antimicrobial agents is associated with the risk of inducing resistance to antimicrobial agents among bacteria (WHO, 2015). In a study of 385 dairy herds in the Netherlands between 2010 and 2012, >70\% of total antibiotic use was for control or treatment of (sub)clinical mastitis (van Werven et al., 2013). Additionally, antimicrobial use was positively associated with AMR in bovine mastitis pathogens (Saini et al., 2012). Therefore, over-reliance on antimicrobial use to reduce the effect of mastitis in dairy herds was not sustainable, whether from political pressure, public perception, research evidence, or other sources (Barkema et al., 2015; Kayitsinga et al., 2017). In the present study, we determined AMR in the 5 most frequently isolated major mastitis pathogens (Staph. aureus, Streptococcus spp., NAS, E. coli, and Klebsiella spp.) from milk samples of CM in large Chinese dairy herds from 2014 to 2017. We monitored a gram-positive cocci and gram-negative bacilli panel containing 11 and 8 antimicrobials, respectively, commonly used in veterinary or human medicine. This was apparently the first time that a nationwide study in China has been conducted to determine AMR in common mastitis pathogens isolated from CM samples in dairy cows.

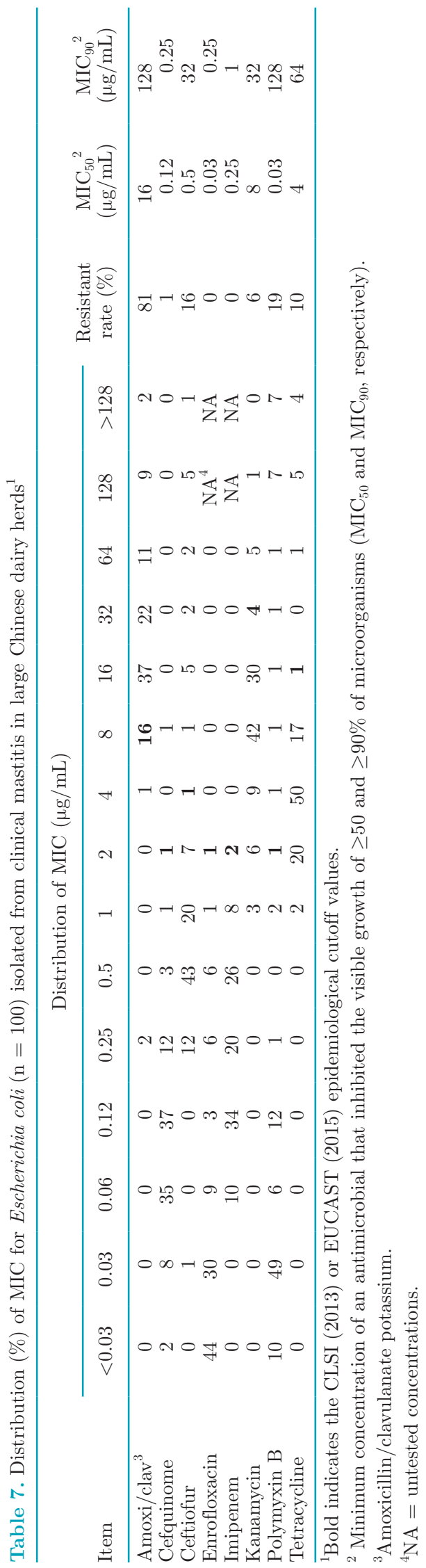

Journal of Dairy Science Vol. 102 No. 3, 2019 
The majority of MIC values for various antibiotics had a very wide distribution, different from reports from Canada and 9 European countries (Saini et al., 2012; de Jong et al., 2018). For these 5 mastitis pathogens, antimicrobials with the highest $\mathrm{MIC}_{90}$ values were penicillin $(>64 \mu \mathrm{g} / \mathrm{mL})$ for Staph. aureus, clindamycin and daptomycin $(>64 \mu \mathrm{g} / \mathrm{mL})$ for NAS, clindamycin (>64 $\mu \mathrm{g} / \mathrm{mL}$ ) for Streptococcus spp., amoxi/clav and ceftiofur (>128 $\mu \mathrm{g} / \mathrm{mL})$ for Klebsiella spp., and amoxi/ clav and ceftiofur $(128 \mu \mathrm{g} / \mathrm{mL})$ for E. coli. Overall, $27 \%$ of isolates in our study were resistant to $\geq 3$ antimicrobials. Our results confirmed that MDR bovine mastitis is a problem in large Chinese dairy herds.

Based on previous studies, penicillin resistance of Staph. aureus is the most common form of AMR among mastitis-causing bacteria (Hendriksen et al., 2008; Kalmus et al., 2011). Among various antimicrobials tested in our study, except for Streptococcus spp., high resistance to penicillin was most common (e.g., $66 \%$ to Staph. aureus and $62 \%$ to NAS). In addition, a high prevalence of the mecA gene was detected in oxacillinresistant strains, especially for strains with MIC 0.5 to $2 \mu \mathrm{g} / \mathrm{mL}$ to oxacillin. However, in a previous study, no significant relationship was found between genotypic content and phenotypic expression represented by methicillin resistance (Al-Khafaji and Flayyih, 2015). Oxacillin is a semi-synthetic penicillin with characteristics of resistance to acids and enzymes. It is effective for gram-positive cocci producing penicillinase, but less effective than penicillin for nonenzymatic bacteria. According to our study, more isolates were oxacillinresistant than penicillin-resistant, consistent with a previous study (Dorothy, 2004). Multidrug resistance to $>2$ antimicrobials was most common in Staph. aureus (33\%), NAS (58\%), and Streptococcus spp. (21\%). Resistance of Staph. aureus was lower in our study than previously reported in China (Shi et al., 2010; Wang et al., 2015; Zhang et al., 2018a), whereas resistance data for Staph. aureus were similar to that reported by others (Rajala-Schultz et al., 2004; Güler et al., 2005). In contrast, clinical Streptococcus spp. mastitis was, in general, still sensitive to penicillin, which differed from reports in other countries (Saini et al., 2012). Additionally, except for NAS and Streptococcus spp., less resistance was detected against third- or fourthgeneration cephalosporins (ceftiofur or cefquinome) compared with first-generation cephalosporins (cefalexin). We noted high resistance rates to tetracycline for these pathogens, especially for Streptococcus spp. (59\%), NAS (34\%), and Klebsiella spp. (32\%), similar to a previous report for China (Yassin et al., 2017) and consistent with spread of tetracycline-resistance genes on a conventional dairy farm (Kyselková et al., 2015).
Antimicrobial treatment of E. coli and Klebsiella spp. has often been considered of limited value; therefore, therapy should be more targeted toward cow survival and reduction of clinical symptoms (Schukken et al., 2012). More recently, it was suggested that third-generation cephalosporin and carbapenems would likely be ineffective against a sizable proportion of $E$. coli or Klebsiella pneumoniae infections in most parts of the world by 2030 (Alvarez-Uria et al., 2018). In the present study, both E. coli and Klebsiella spp. were often resistant to amoxi/clav ( 81 and $38 \%$, respectively), higher than reported by Schukken et al. (2012) and Alvarez-Uria et al. (2018). Additionally, our study had a lower prevalence of MDR in E. coli and Klebsiella spp. than reported by others (Schukken et al., 2012; Alvarez-Uria et al., 2018).

In the present study, 2 antibiotics critical for human use (daptomycin and vancomycin) were tested for gram-positive cocci, whereas 2 others (imipenem and polymyxin B) were tested for gram-negative bacteria. Surprisingly, in Staph. aureus, resistance to daptomycin and vancomycin was only 8 and $3 \%$, respectively, whereas 21 and $20 \%$ of NAS and 5 and $9 \%$ of Streptococcus spp. isolated from $\mathrm{CM}$ were resistant to daptomycin and vancomycin, respectively; this was different from other countries, for example Canada and Uganda (Saini et al., 2012; Kateete et al., 2013; Nobrega et al., 2018). Since 1989, prevalence of vancomycin-resistant infections has increased exponentially in humans. It is recommended that vancomycin, a drug highly critical for human medicine, should only be used to treat humans infected with methicillin-resistant staphylococci (Zheng et al., 2018). The observed vancomycin-resistant isolates in bovine CM in our study were a risk to public health.

Compared with 8 European countries (Thomas et al., 2015), resistance rates were higher in our Chinese study. We found major differences in antimicrobial consumption patterns among countries (Mather et al., 2011), reflecting a combination of factors including national guidelines for proper antimicrobial use, veterinarian prescription patterns, pharmaceutical marketing strategies, animal demographics, and specific needs for antimicrobials in specific countries (ESVAC, 2012). Major differences in occurrence of AMR have also been observed among bacteria (e.g., E. coli) isolated from different countries (Chantziaras et al., 2014; ECDC et al., 2015). Therefore, it is very likely that our findings arise from the use or abuse of these antimicrobial agents in IMI in China.

This investigation highlighted the worrisome trend of increased AMR rates in Chinese dairy herds. However, we must highlight that results of our study cannot 
be generalized to the entire Chinese dairy industry, especially because small farms were not recruited.

\section{CONCLUSIONS}

In these large Chinese dairy herds, Staph. aureus and Streptococcus spp. isolates were highly resistant to penicillin $(66 \%)$ and tetracycline $(59 \%)$, whereas NAS were more often resistant to oxacillin (84\%) and penicillin $(62 \%)$. Both E. coli and Klebsiella spp. were frequently resistant to amoxicillin-clavulanate potassium (81 and $38 \%$ ); however, resistance rates against 4 antimicrobials that should be reserved for use in human medicine (daptomycin, vancomycin, imipenem, and polymyxin B), ranged from 3 to $21 \%$. A high proportion of MDR was frequently observed, where clindamycin-cephalexintetracycline and enrofloxacin-cephalexin-penicillin were the most commonly observed patterns for Staph. aureus, and enrofloxacin-oxacillin-penicillin-tetracycline and clindamycin-enrofloxacin-tetracycline were the most frequent multi-drug resistant patterns for NAS and Streptococcus spp., respectively. This investigation highlighted the worrisome trend of increased prevalence of AMR in large Chinese dairy herds.

\section{ACKNOWLEDGMENTS}

This study was financially supported by the National Key R\&D Project (No. 2016YFD0501203), the National Natural Science Foundation of China (No. 31772813, 31572587, 31660730 and 31550110200) and the High-end Foreign Experts Recruitment Program (No. GDT20171100013).

\section{REFERENCES}

Abebe, R., H. Hatiya, M. Abera, B. Megersa, and K. Asmare. 2016. Bovine mastitis: prevalence, risk factors and isolation of Staphylococcus aureus in dairy herds at Hawassa milk shed, South Ethiopia. BMC Vet. Res. 12:270.

Al-Khafaji, M. H., and M. T. Flayyih. 2015. Relationship between methicillin resistance and the presence of $f e m A$ and $m e c A$ genes in coagulase positive and negative staphylococci isolated from milk and cheese. World J. Exp. Biosci. 3:50-56.

Ali, T., S. U. Rahman, L. Zhang, M. Shahid, D. Han, J. Gao, S. Zhang, P. L. Ruegg, U. Saddique, and B. Han. 2017. Characteristics and genetic diversity of multi-drug resistant extended-spectrum betalactamase (ESBL)-producing Escherichia coli isolated from bovine mastitis. Oncotarget 8:90144-90163.

Alvarez-Uria, G., S. Gandra, S. Mandal, and R. Laxminarayan. 2018. Global forecast of antimicrobial resistance in invasive isolates of Escherichia coli and Klebsiella pneumoniae. Int. J. Infect. Dis. 68:50-53.

Barkema, H. W., Y. H. Schukken, and R. N. Zadoks. 2006. Invited review: The role of cow, pathogen, and treatment regimen in the therapeutic success of bovine Staphylococcus aureus mastitis. J. Dairy Sci. 89:1877-1895.

Barkema, H. W., M. A. G. von Keyserlingk, J. P. Kastelic, T. J. G. M. Lam, C. Luby, J.-P. Roy, S. J. LeBlanc, G. P. Keefe, and D. F.
Kelton. 2015. Invited review: Changes in the dairy industry affecting dairy health and welfare. J. Dairy Sci. 98:7426-7445.

Chantziaras, I., F. Boyen, B. Callens, and J. Dewulf. 2014. Correlation between veterinary antimicrobial use and antimicrobial resistance in food-producing animals: A report on seven countries. J. Antimicrob. Chemother. 69:827-834.

CLSI. 2013. Performance standards for antimicrobial disk and dilution susceptibility tests for bacteria isolated from animals; approved standard. 4th ed. CLSI document VET01-A4. Clinical Laboratory Standards Institute (CLSI), Wayne, PA.

CLSI. 2017. Performance standards for antimicrobial susceptibility testing; CLSI document M100-S27. Clinical Laboratory Standards Institute (CLSI), Wayne, PA.

de Jong, A. J., F. E. Garch, S. Simjee, H. Moyaert, M. Rose, M. Youala, E. Siegwart, and VetPath Study Group. 2018. Monitoring of antimicrobial susceptibility of udder pathogens recovered from cases of clinical mastitis in dairy cows across Europe: VetPath results. Vet. Microbiol. 213:73-81. PubMed

Dorothy, D. D. 2004. Comparison of resistance to the antibiotics penicillin, erythromycin, oxacillin, chloramphenicol and vancomycin in Staphylococcus aureus isolated from healthy adults in the United States of America and Mexico. Rev. Med. Univ. Veracruz. 4:5-9.

ECDC, EFSA, and ENA. 2015. ECDC/EFSA/EMA first joint report on the integrated analysis of the consumption of antimicrobial agents and occurrence of antimicrobial resistance in bacteria from humans and food producing animals. EFSA J. 13:4006.

ECDC. 2017. Summary of the latest data on antibiotic resistance in the European Union. European Centre for Disease Prevention and Control. Stockholm. Accessed Sep. 14, 2018. https://ecdc .europa.eu/en/publications-data/summary-latest-data-antibiotic -resistance-european-union.

ESVAC. 2012. European Medicines Agency. Second ESVAC Report. European Surveillance of Veterinary Antimicrobial Consumption Report (ESVAC). Sales of veterinary antimicrobial agents in 19 EU/EEA countries in 2010. Accessed Sep. 14, 2018. http://www .ema.europa.eu/docs/en_GB/document_library/Report/2012/ 10/WC500133532.pdf.

EUCAST. 2015. The European committee on antimicrobial susceptibility testing. Accessed Sep. 14, 2018. http://www.eucast.org/.

Frank, J. A., C. I. Reich, S. Sharma, J. S. Weisbaum, B. A. Wilson, and G. J. Olsen. 2008. Critical evaluation of two primers commonly used for amplification of bacterial 16S rRNA genes. Appl. Environ. Microbiol. 74:2461-2470.

Gao, J., H. W. Barkema, L. Zhang, G. Liu, Z. Deng, L. Cai, R. Shan, S. Zhang, J. Zou, J. P. Kastelic, and B. Han. 2017. Incidence of clinical mastitis and distribution of pathogens on large Chinese dairy farms. J. Dairy Sci. 100:4797-4806.

Gao, J., M. Ferreri, F. Yu, X. Liu, L. Chen, J. Su, and B. Han. 2012 Molecular types and antibiotic resistance of Staphylococcus aureus, isolates from bovine mastitis in a single herd in China. Vet. J. 192:550-552.

Güler, L., U. Ok, K. Gündüz, Y. Gülcü, and H. H. Hadimli. 2005. Antimicrobial susceptibility and coagulase gene typing of Staphylococcus aureus isolated from bovine clinical mastitis cases in Turkey. J. Dairy Sci. 88:3149-3154.

Hendriksen, R. S., D. J. Mevius, A. Schroeter, C. Teale, D. Meunier, P. Butaye, A. Franco, A. Utinane, A. Amado, M. Moreno, C. Greko, K. Stärk, C. Berghold, A. L. Myllyniemi, D. Wasyl, M. Sunde, and F. M. Aarestrup. 2008. Prevalence of antimicrobial resistance among bacterial pathogens isolated from cattle in different European countries: 2002-2004. Acta Vet. Scand. 50:28.

Hogeveen, H., and M. Van Der Voort. 2017. Assessing the economic impact of an endemic disease: The case of mastitis. Rev. Sci. Tech. 36:217-226.

Kalmus, P., B. Aasmäe, A. Kärssin, T. Orro, and K. Kask. 2011. Udder pathogens and their resistance to antimicrobial agents in dairy cows in Estonia. Acta Vet. Scand. 53:4.

Kateete, D. P., U. Kabugo, H. Baluku, L. Nyakarahuka, S. Kyobe, M. Okee, C. F. Najjuka, and M. L. Joloba. 2013. Prevalence and antimicrobial susceptibility patterns of bacteria from milkmen and 
cows with clinical mastitis in and around Kampala, Uganda. PLoS One 8:e63413.

Kayitsinga, J., R. L. Schewe, G. A. Contreras, and R. J. Erskine. 2017. Antimicrobial treatment of clinical mastitis in the eastern United States: The influence of dairy farmers' mastitis management and treatment behavior and attitudes. J. Dairy Sci. 100:1388-1407.

Krömker, V., and S. Leimbach. 2017. Mastitis treatment-reduction in antibiotic usage in dairy cows. Reprod. Domest. Anim. 52(Suppl 3):21-29.

Kyselková, M., J. Jirout, N. Vrchotová, H. Schmitt, and D. Eihottova. 2015. Spread of tetracycline resistance genes at a conventional dairy farm. Front. Microbiol. 6:536.

Liu, H., S. Li, L. Meng, L. Dong, S. Zhao, X. Lan, J. Wang, and N. Zheng. 2017. Prevalence, antimicrobial susceptibility, and molecular characterization of Staphylococcus aureus isolated from dairy herds in northern China. J. Dairy Sci. 100:8796-8803.

Liu, Y., G. Liu, W. Liu, Y. Liu, T. Ali, W. Chen, J. Yin, and B. Han. 2014. Phylogenetic group, virulence factors and antimicrobial resistance of Escherichia coli, associated with bovine mastitis. Res. Microbiol. 165:273-277.

Magiorakos, A. P., A. Srinivasan, R. B. Carey, Y. Carmeli, M. E. Falagas, C. G. Giske, S. Harbarth, J. F. Hindler, G. Kahlmeter, B. Olsson-Liljequist, D. L. Paterson, L. B. Rice, J. Stelling, M. J. Struelens, A. Vatopoulos, J. T. Weber, and D. L. Monnet. 2012. Multidrug-resistant, extensively drug-resistant and pandrug-resistant bacteria: An international expert proposal for interim standard definitions for acquired resistance. Clin. Microbiol. Infect. $18: 268-281$.

Mather, A. E., M. J. Denwood, D. T. Haydon, L. Matthews, D. J. Mellor, J. E. Coia, D. J. Brown, and S. W. Reid. 2011. The prevalences of Salmonella genomic island 1 variants in human and animal Salmonella Typhimurium DT104 are distinguishable using a Bayesian approach. PLoS One 6:e27220.

NMC. 1999. Laboratory Handbook on Bovine Mastitis. National Mastitis Council Inc., Madison, WI.

Nobrega, D. B., S. Naushad, S. A. Naqvi, L. A. Z. Condas, V. Saini, J. P. Kastelic, C. Luby, J. De Buck, and H. W. Barkema. 2018. Prevalence and genetic basis of antimicrobial resistance in nonaureus staphylococci isolated from Canadian dairy herds. Front. Microbiol. 9:256.

Oliver, S. P., and S. E. Murinda. 2012. Antimicrobial resistance of mastitis pathogens. Vet. Clin. North Am. Food Anim. Pract. 28:165185

Oliver, S. P., S. E. Murinda, and B. M. Jayarao. 2011. Impact of antibiotic use in adult dairy cows on antimicrobial resistance of veterinary and human pathogens: a comprehensive review. Foodborne Pathog. Dis. 8:337-355.

Pinzón-Sánchez, C., V. E. Cabrera, and P. L. Ruegg. 2011. Decision tree analysis of treatment strategies for mild and moderate cases of clinical mastitis occurring in early lactation. J. Dairy Sci. 94:1873-1892.

Rajala-Schultz, P. J., K. L. Smith, J. S. Hogan, and B. C. Love. 2004. Antimicrobial susceptibility of mastitis pathogens from first lactation and older cows. Vet. Microbiol. 102:33-42.

Saini, V., J. T. McClure, D. Léger, G. P. Keefe, D. T. Scholl, D. W. Morck, and H. W. Barkema. 2012. Antimicrobial resistance profiles of common mastitis pathogens on Canadian dairy farms. J. Dairy Sci. 95:4319-4332.
Schukken, Y., M. Chuff, P. Moroni, A. Gurjar, C. Santisteban, F. Welcome, and R. N. Zadoks. 2012. The "other" gram-negative bacteria in mastitis: Klebsiella, Serratia, and more. Vet. Clin. North Am. Food Anim. Pract. 28:239-256.

Shi, D., Y. Hao, A. Zhang, B. Wulan, and X. Fan. 2010. Antimicrobial resistance of Staphylococcus aureus isolated from bovine mastitis in China. Transbound. Emerg. Dis. 57:221-224.

Thomas, V., A. de Jong, H. Moyaert, S. Simjee, F. El Garch, I. Morrissey, H. Marion, and M. Vallé. 2015. Antimicrobial susceptibility monitoring of mastitis pathogens isolated from acute cases of clinical mastitis in dairy cows across Europe: VetPath results. Int. J. Antimicrob. Agents 46:13-20.

Vakkamäki, J., S. Taponen, A. M. Heikkilä, and S. Pyörälä. 2017. Bacteriological etiology and treatment of mastitis in Finnish dairy herds. Acta Vet. Scand. 59:33.

Van Boeckel, T. P., C. Brower, M. Gilbert, B. T. Grenfell, S. A. Levin, T. P. Robinson, A. Teillant, and R. Laxminarayan. 2015. Global trends in antimicrobial use in food animals. Proc. Natl. Acad. Sci. USA 112:5649.

van Werven, T., F. Waldeck, A. H. Souza, S. Floch, and M. Englebienne. 2013. Comparison of two intravaginal progesterone releasing devices (PRID-Delta vs CIDR) in dairy cows: Blood progesterone profile and field fertility. Anim. Reprod. Sci. 138:143-149.

Verbeke, J., M. Van Poucke, L. Peelman, S. Piepers, and S. De Vliegher. 2014. Associations between CXCR1 polymorphisms and pathogen-specific incidence rate of clinical mastitis, test-day somatic cell count, and test-day milk vield. J. Dairy Sci. 97:7927-7939.

Wang, D., Z. C. Wang, Z. T. Yan, J. Y. Wu, T. Ali, J. J. Li, Y. L. Lv, and B. Han. 2015. Bovine mastitis Staphylococcus aureus: Antibiotic susceptibility profile, resistance genes and molecular typing of methicillin-resistant and methicillin-sensitive strains in China. Infect. Genet. Evol. 31:9-16.

WHO. 2015. Global action plan on antimicrobial resistance. Accessed Sep. 14, 2018. http://www.who.int/drugresistance/global_action _plan/en/.

Xiao, Y. H., C. G. Giske, Z. Q. Wei, P. Shen, A. Heddini, and L. J. Li. 2011. Epidemiology and characteristics of antimicrobial resistance in China. Drug Resist. Updat. 14:236.

Yassin, A. K., J. S. Gong, P. Kelly, G. W. Lu, L. Guardabassi, L. J. Wei, X. Han, H. X. Qiu, S. Price, D. R. Cheng, and C. M. Wang. 2017. Antimicrobial resistance in clinical Escherichia coli isolates from poultry and livestock, China. PLoS One 12:e0185326.

Zhang, L., J. Gao, H. W. Barkema, T. Ali, G. Liu, Y. Deng, S. Naushad, J. P. Kastelic, and B. Han. 2018a. Virulence gene profiles: Alpha-hemolysin and clonal diversity in Staphylococcus aureus isolates from bovine clinical mastitis in China. BMC Vet. Res. 14:63.

Zhang, S., S. Piepers, R. Shan, L. Cai, S. Mao, J. Zou, T. Ali, S De Vliegher, and B. Han. 2018b. Phenotypic and genotypic characterization of antimicrobial resistance profiles in Streptococcus dysgalactiae isolated from bovine clinical mastitis in 5 provinces of China. J. Dairy Sci. 101:3344-3355.

Zheng, X., A. D. Berti, S. McCrone, M. Roch, A. E. Rosato, W. E. Rose, and B. Chen. 2018. Combination antibiotic exposure selectively alters the development of vancomycin intermediate resistance in Staphylococcus aureus. Antimicrob. Agents Chemother. 62:e02100-e02117. 